\title{
Influence of microstructural evolution of Al-Si coated UHSS on its tribological behaviour against tool steel at elevated temperatures
}

\author{
Materials tribology
}

\section{Pelcastre*, J. Hardell, A. Rolland and B. Prakash}

Division of Machine Elements, Luleå University of Technology, Luleå SE-971 87 Sweden

* Corresponding author: Leonardo Pelcastre ( leonardo.pelcastre@ltu.se )

\begin{abstract}
In recent years, the usage of the hot stamping process has increased due to the high demands for production of ultra-high strength steels (UHSS). In particular, more studies are being carried out pertaining to the Al-Si coated UHSS to understand its behaviour during the forming process as well as the performance of the produced parts. The Al-Si coating is
\end{abstract} applied to the UHSS with the aim of reducing decarburisation and to avoid the formation of thick oxide scales on the workpiece during the heating stage. Usage of the Al-Si coating has the added benefit of greatly improving the corrosion resistance and paintability of the produced components [1, 2].

An important aspect of the AlSi coated UHSS is the phase transformations in the coating that take place during heating. $\mathrm{Al}$ and the Si from the coating combine with the Fe from the

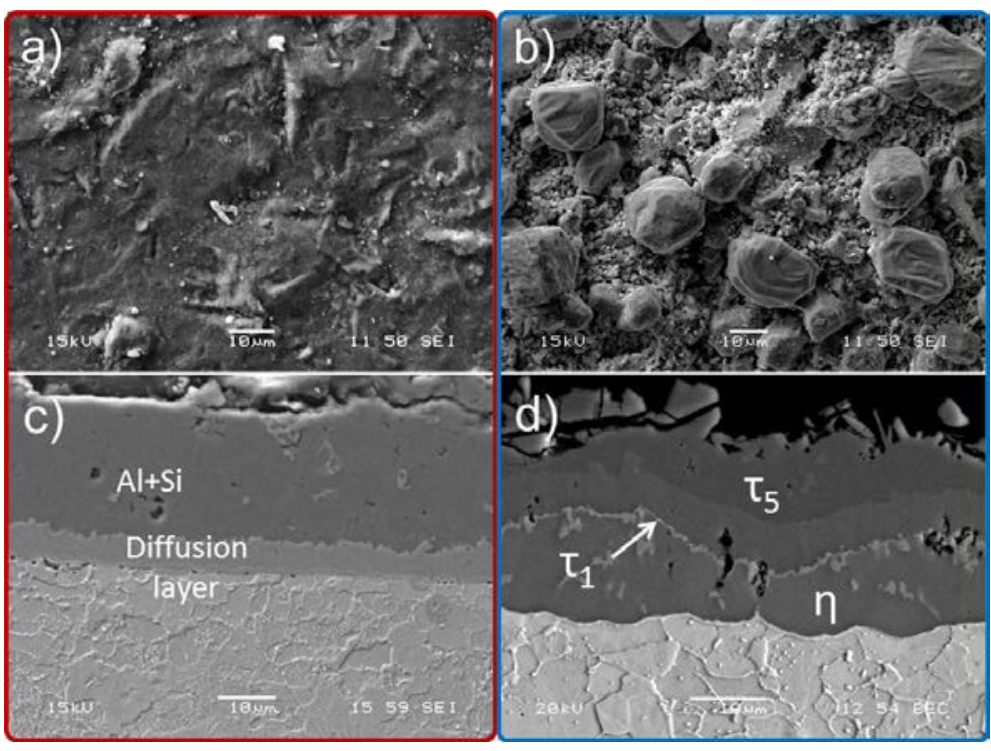

Figure 1 Top surface and cross-section of the Al-Si coating; a) and c) in the as delivered state and b) and d) after exposure to elevated temperature

steel substrate to form a range of intermetallic phases which have different physical and mechanical properties [1-3]. Furthermore, the Al-Si coating undergoes surface morphological changes as a result of melting of unalloyed aluminium during exposure to elevated temperatures. Some of the typical changes observed in the coating are illustrated in Figure 1.

As in any diffusive process, time and temperature are key factors for the occurrence of phase transformations. Changes in the process conditions affect the microstructure of the coating and this in turn affects its response during the forming operation. This is particularly important for the tribological response, as all of the evolutions observed are at the nearsurface or surface regions.

The tribological behaviour of the Al-Si coated UHSS interacting with the forming tool is of major concern as it has an influence on the quality of the produced parts as well as on wear 
and surface damage of the forming tools. Galling, a severe form of adhesive wear, is a common and critical wear mechanism that occurs during forming of the Al-Si coated UHSS. Most of the research concerning this type of wear has focused on the study of different tool materials and surface modification methods of the forming tools [4-6]. However, limited work has been done concerning the influence of heating conditions on the evolution of the coating and its effect on the tribological behaviour during interaction with the tool steel.

In this work, different heat treatment parameters of the coated UHSS and the galling response have been analysed. Two heating temperatures $\left(700\right.$ and $\left.900^{\circ} \mathrm{C}\right)$ and three different soaking times ( 0,4 and $20 \mathrm{~min}$ ) were chosen for the analysis. The heat treatments were carried out within the chamber of the tribometer so as to compare the phases observed with the ones developed during the tribological tests. In Figure 2, the obtained microstructure for each of the conditions is shown.

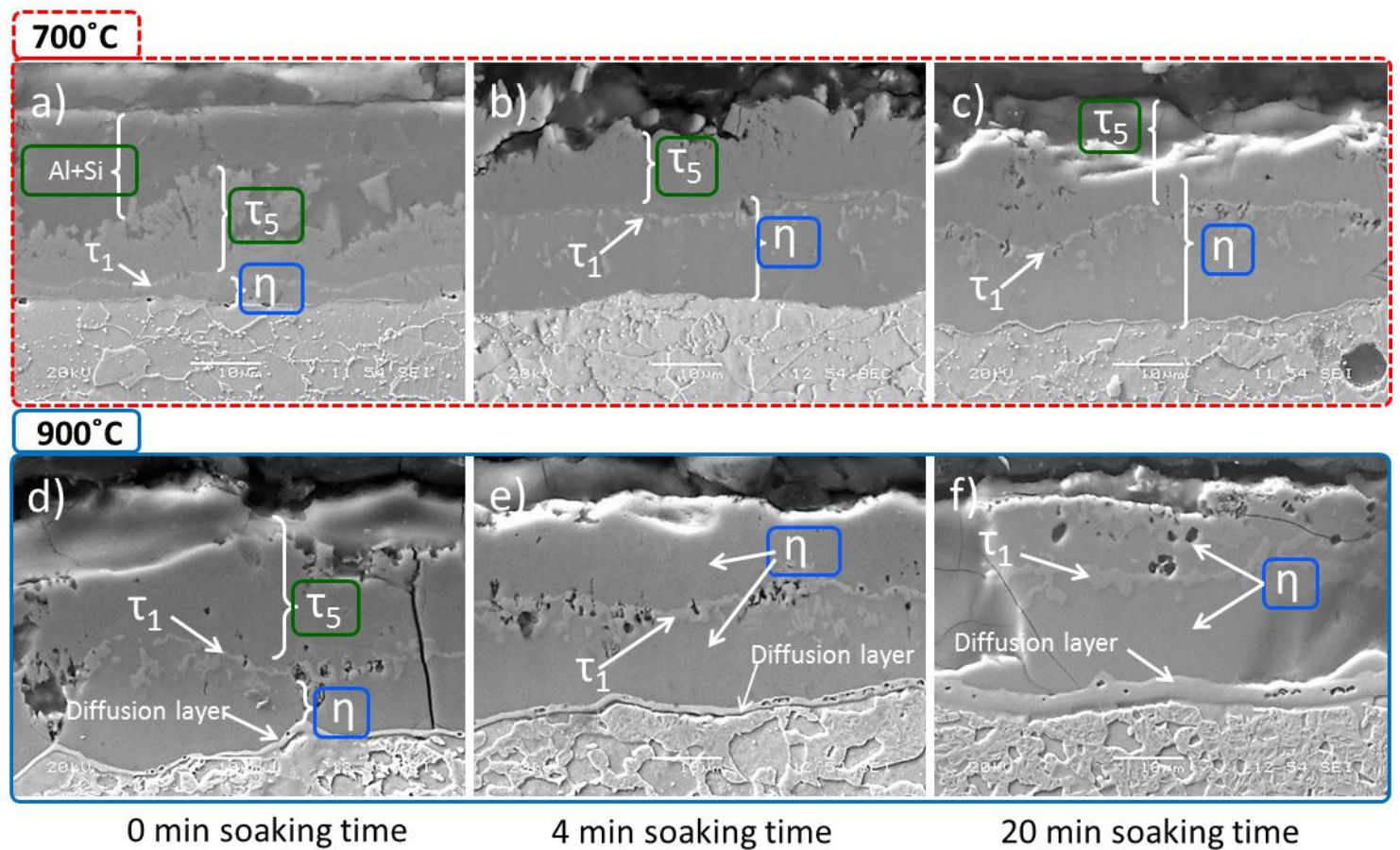

Figure 2 Microstructure of the coating for all the conditions used. Figures a) to c) show 0, 4 and 20 minutes at $700^{\circ} \mathrm{C}$ and Figures d) to f) show 0,4 and 20 minutes at $900^{\circ} \mathrm{C}$

Severe galling was observed for all soaking times at $700^{\circ} \mathrm{C}$ and the main mechanism responsible for the initiation of galling was severe adhesion. Thick transfer layers were observed on the tool steel specimen after sliding against the Al-Si coating heated for 0 min soaking time and furthermore, the transfer layer underwent smearing (Figure 3a). The use of long soaking times slightly reduced the severity of galling at $700^{\circ} \mathrm{C}$ and the smearing of the transferred layer was noticeably reduced (Figure 3b).

At $900^{\circ} \mathrm{C}$ and 0 min soaking time, material transfer was also initiated through severe adhesion and lumps of agglomerated debris along with smearing of the transferred material were observed. When increasing the soaking time from 0 to $4 \mathrm{~min}$, material transfer was considerably reduced and instead abrasive wear of the tool steel was observed. 

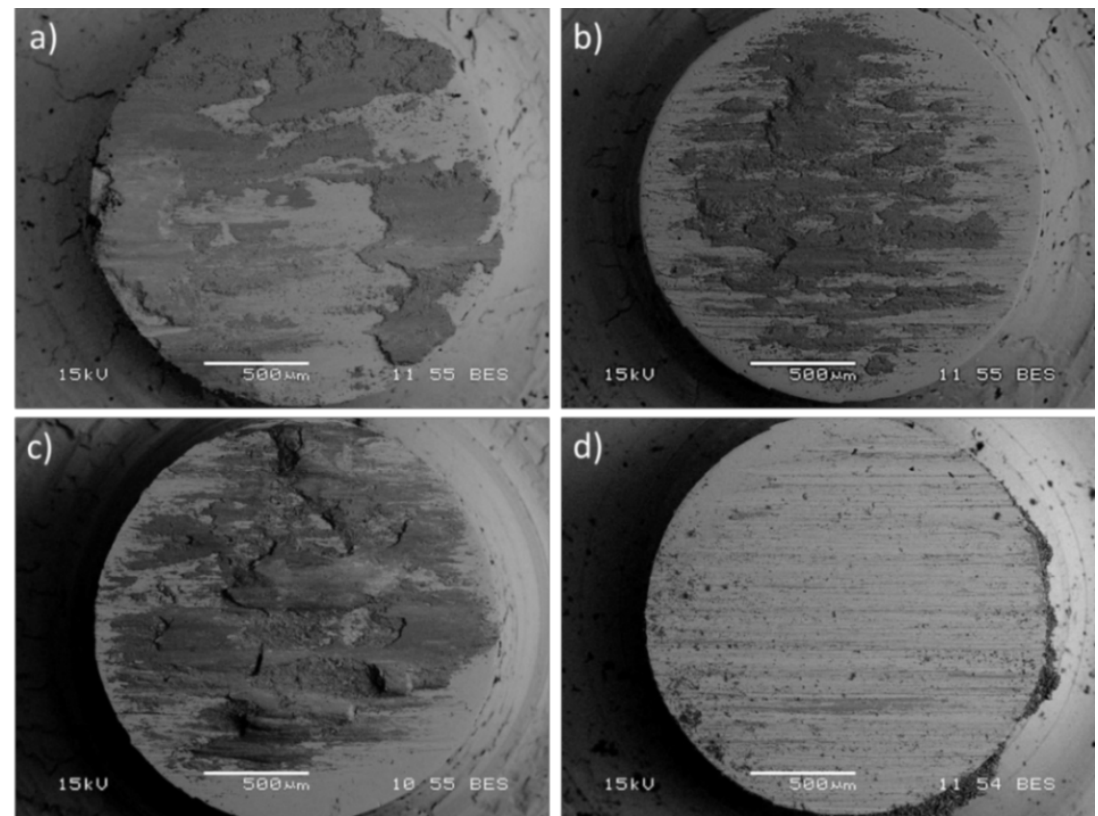

Figure 3 Tool steel pin specimens after tribological test at $700^{\circ} \mathrm{C}$ with soaking time of a) 0 min and b) 20 min; and at $900^{\circ} \mathrm{C}$ with soaking time of c) 0 min and d) 20 min

It has been observed that the tribological response of the Al-Si coated UHSS is directly linked to the intermetallic phases formed during heating. From the different phases developed, $\eta$ showed the best performance in terms of reduced material transfer when interacting with uncoated tool steel.

\section{Acknowledgements}

This work has been carried out with financial support from the Centre for High Performance Steel at Luleå University of Technology and the authors gratefully acknowledge their support. The authors would also like to thank Gestamp HardTech for providing test specimens for these studies and also thank them for their active interest in this work

\section{References:}

1. M. Suehiro, K. Kusumi, J. Maki, M. Ohgami, T. Miyakoshi, Properties of aluminium coated steels for hot forming, in: Nippon steel technical report No. 88, July 2003

2. R. Grigorieva, P. Drillet, J.-M. Mataigne and A. Redjaïmia. Phase transformations in the Al-Si coating during the austenitization step. Solid state phenomena, 172-174 (2011) pp 784-790

3. R. Veit, H. Hofmann, R. Kolleck and S. Sikora. Investigation of the phase formation of AlSi-coatings for hot stamping of boron alloyed steel. In: AIP conf. proc. 1315, 769 (2011)

4. J. Kondratiuk, P. Kuhn, Tribological investigation on friction and wear behaviour of coatings for hot sheet metal forming, in: Wear 270 (2011) 839-849

5. L. Pelcastre, J. Hardell and B. Prakash. Investigations into the occurrence of galling during hot forming of Al-Si coated high-strength steel. Proc. IMech Part J: J. Engineering tribology. 2011 (225) 487-498

6. L. Pelcastre, J. Hardell and B. Prakash. Galling mechanisms during interaction of tool steel and Al-Si coated ultra-high strength steel at elevated temperature. Tribology International 67(2013) 263-271

KEYWORDS: Surfaces:Metallurgical Analysis, Friction:Unlubricated Friction, Wear:Galling.

Keyword:Other: high temperature tribology 